\title{
A young marathon runner with severe aortic coarctation and bicuspid aortic valve disease complicated by contained aortic rupture
}

\author{
Maks Mihalj, MD, ${ }^{\mathrm{a}}$ Vladimir Makaloski, MD, ${ }^{\mathrm{a}}$ Samuel Hurni, MD, ${ }^{\mathrm{a}}$ Jan-Oliver Friess, MD, \\ Carlo Melis, MD, ${ }^{\mathrm{c}}$ Thierry P. Carrel, MD, ${ }^{\mathrm{a}}$ and Florian S. Schoenhoff, MD $^{\mathrm{a}}$
}

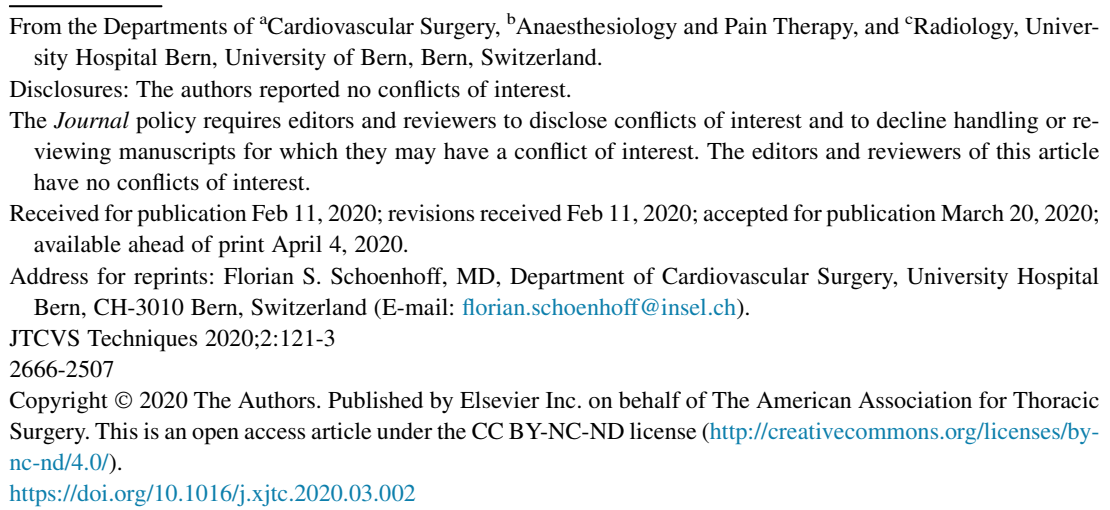

A 17-year-old competitive athlete with no previous medical history was admitted after acute onset of chest and back pain. A week before the event, he took part in a marathon but was not able to finish due to spasms in his lower extremities.

Findings of the physical examination revealed a clinically stable patient with systolic and diastolic heart murmur and arterial hypertension. Echocardiography revealed the presence of an aortic root aneurysm and a bicuspid aortic valve with severe regurgitation, as well as pericardial effusion. Creatine kinase (CK) levels were markedly elevated at $3372 \mathrm{U} / \mathrm{L}$ (reference value $<190 \mathrm{U} / \mathrm{L}$ ). Systolic pressure gradient between upper and lower extremities was $30 \mathrm{~mm} \mathrm{Hg}$.

Computed tomography scanning revealed an $80-\mathrm{mm}$ aneurysm of the ascending aorta with a lesion suggesting contained rupture at the level of the right pulmonary artery, as well as severe coarctation of the aorta distal to the left subclavian artery (Figure 1, $A$ and $C$ ) with extensive collateral circulation (Figure 1, $A, E$, and $F$ ).

Emergency surgery comprised aortic root replacement and replacement of the entire ascending aorta using hypothermic circulatory arrest (HCA) for the distal aortic anastomosis. The aortic valve was bicuspid, Sievers type 1 with R-L fusion pattern. A large tear in the posterior aspect of the ascending aorta confirmed the findings of the preoperative imaging (Figure 1, G). Pressure monitoring during surgery was performed via both radial arteries as well as the left femoral artery. While the initial gradient was $30 \mathrm{~mm} \mathrm{Hg}$, it dropped to $10 \mathrm{~mm} \mathrm{Hg}$ (mean arterial pressure) during cardiopulmonary bypass (Figure 2). We stable.

\section{DISCUSSION}

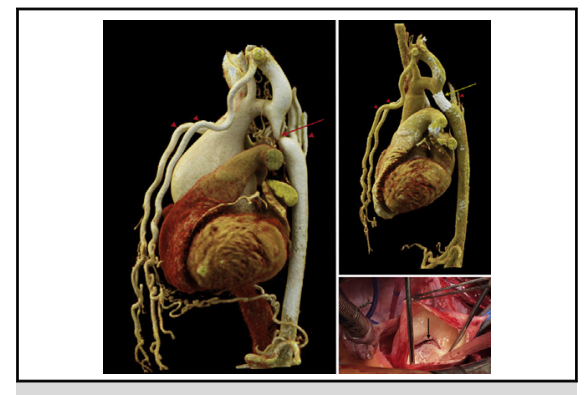

Large aortic aneurysm in the presence of aortic coarctation, complicated by intimal tear.

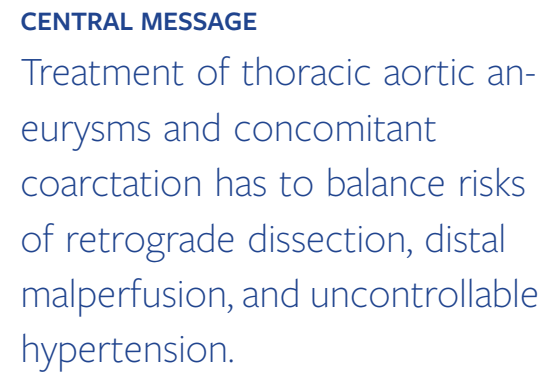

See Commentaries on pages 124 and 126.

prepared for double arterial cannulation (right axillary and femoral artery) but did not introduce a second line, as the patient was cooling homogenously and lactate levels were

Given the extensive collateralization, the coarctation was not addressed at the time of surgery. On postoperative day 8 , a balloon-expandable covered stent was implanted at the level of the proximal descending aorta, reducing the systolic pressure gradient to $<5 \mathrm{~mm} \mathrm{Hg}$ (Figure 1, C and $D$ ). Computed tomographic angiography after 4 weeks demonstrated good results (Figure 1, B). The patient provided informed consent for the publication of the study data.

Our patient exhibited the well-known triad of coarctation, bicuspid aortic valve, and aortic aneurysm. ${ }^{1-4}$ Nevertheless, the presentation was remarkable, as he has not only been asymptomatic to this day but even had been performing long-distance running for several years. He frequently complained of spasms in his lower extremities but attributed 

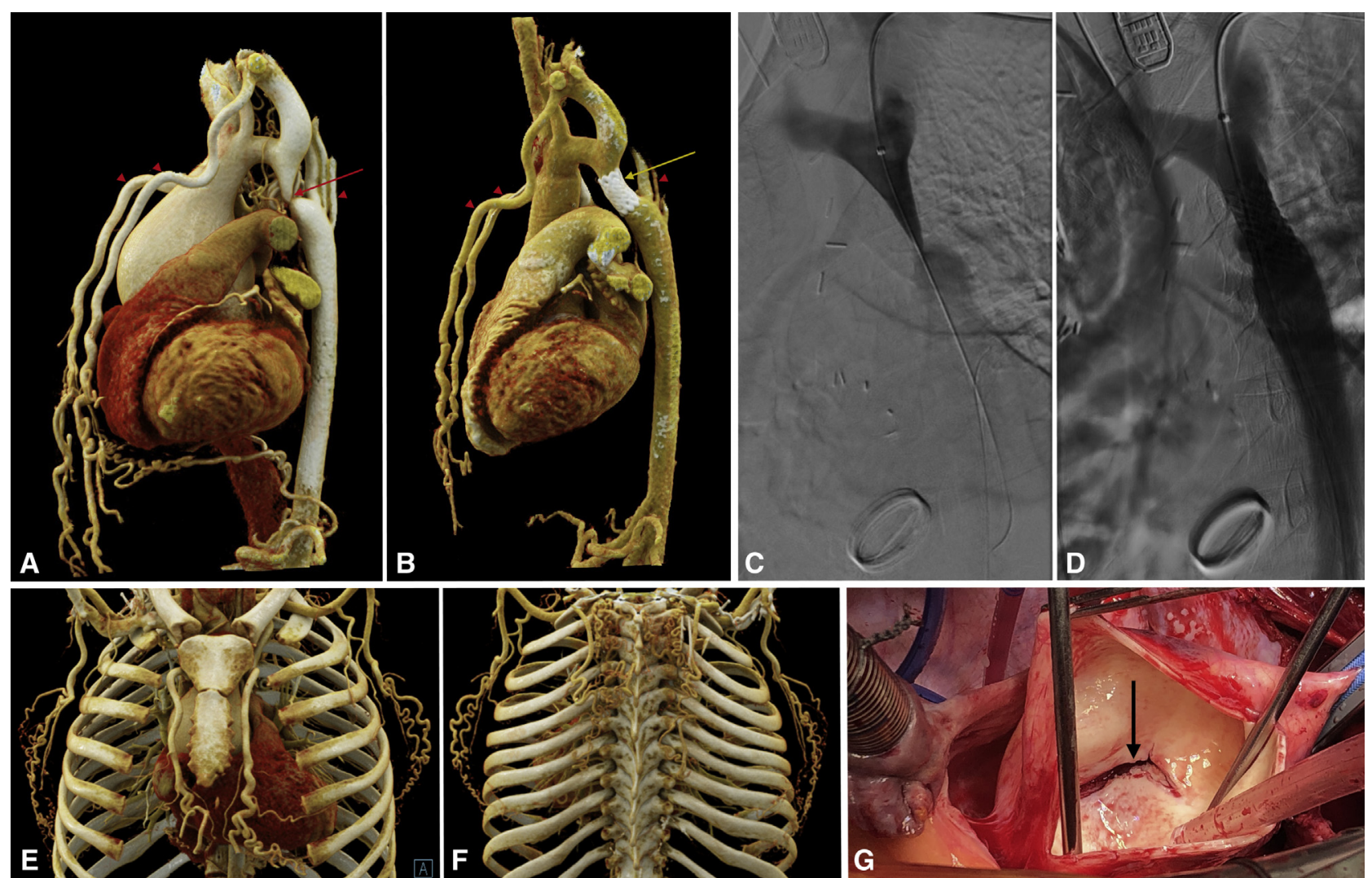

FIGURE 1. A, Aortic coarctation (red arrow) with strong collateralization (red arrowheads) and large aneurysm of the ascending aorta and aortic root. B, After aortic root and partial arch replacement, followed by covered stent implantation (yellow arrow). Aortic angiography at level of aortic coarctation before (C) and after aortic covered stent implantation (D). E and F, Strong arterial collateralization of the thorax. G, Intraoperative picture of ascending aortic aneurysm, with large intimal tear (black arrow).

these to his strenuous training. The markedly elevated CK levels days after running suggests that he was indeed experiencing ischemia when exercising. In a recent study, mean CK levels 24 hours after a marathon were $1443 \pm 1533 \mathrm{U} / \mathrm{L}$, whereas mean levels after 8 days were almost normalized with $166 \pm 19 \mathrm{U} / \mathrm{L} .{ }^{5}$ While many adult patients with coarctation suffer from difficulty to control hypertension, our patient exhibited only moderate blood pressure elevation during exercise testing 6 weeks after the event and monotherapy with an angiotensin receptor blocker.

The patient presented with large aneurysm of the aortic root. The distal ascending aorta as well as the aortic arch were not enlarged or dissected but actually rather small. We did not perform a single-stage hybrid approach with

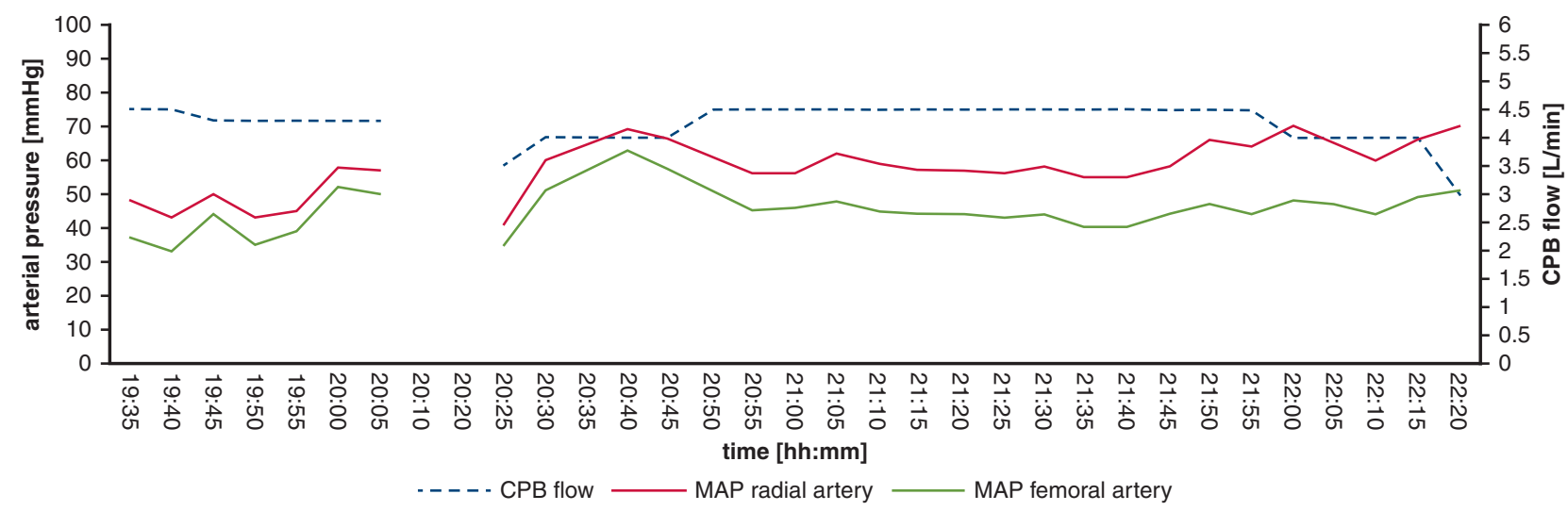

FIGURE 2. Pressure and flow chart during $C P B$. Note the steady pressure gradient between radial and femoral artery during $C P B$. $C P B$, Cardiopulmonary bypass; MAP, mean arterial pressure. 
stent deployment during HCA, as lower-body perfusion was not critical and a prolonged HCA could be avoided. A single-stage approach using a frozen elephant trunk (FET) was deemed unsuitable, as arch replacement was not necessary and the radial force of the stent-graft portion of the FET would most probably not have been sufficient to open up the coarctation. Furthermore, the smallest FET available was $24 \mathrm{~mm}$ and the risk of infolding would have been very high. Ascending-descending aortic bypass is usually reserved for situations in which a complex re-do should be avoided and not the procedure of choice in a patient with stenosis of a short segment.

Instead, a 2-stage hybrid approach was chosen for addressing the coarctation, as lactate levels declined after reperfusion was started and it became clear that distal perfusion was sufficient. Delaying the second procedure in selected cases might be beneficial, eg, in terms of kidney function. In case the dissection would have extended into the stenosed segment, immediate stenting would have been necessary.

In patients with large aneurysms of the ascending aorta and concomitant aortic coarctation, the risk of retrograde type A dissection during percutaneous intervention of the coarctation has to be balanced against the risk for distal malperfusion during cardiopulmonary bypass and hypothermic circulatory arrest, as well as the difficulty to control hypertension in the perioperative period. Considering a stepwise approach is reasonable.

\section{References}

1. Torok RD, Campbell MJ, Fleming GA, Hill KD. Coarctation of the aorta: management from infancy to adulthood. World J Cardiol. 2015;7:765-75.

2. Brown ML, Burkhart HM, Connolly HM, Dearani JA, Cetta F, Li Z, et al. Coarctation of the aorta. Lifelong surveillance is mandatory following surgical repair. J Am Coll Cardiol. 2013;62:1020-5.

3. Schaefer BM, Lewin MB, Stout KK, Gill E, Prueitt A, Byers PH, et al. The bicuspid aortic valve: an integrated phenotypic classification of leaflet morphology and aortic root shape. Heart. 2008;94:1634-8.

4. Erbel R, Aboyans V, Boileau C, Bossone E, Bartolomeo RD, Eggebrecht H, et al. ESC guidelines on the diagnosis and treatment of aortic diseases: document covering acute and chronic aortic diseases of the thoracic and abdominal aorta of the adult. The task force for the diagnosis and treatment of aortic diseases of the European Society of Cardiology (ESC). Eur Heart J. 2014;35: 2873-926.

5. Bernat-Adel MD, Collado-Boira EJ, Moles-Julio P, Panizo-González N, MartínezNavarro I, Hernando-Fuster B, et al. Recovery of inflammation, cardiac, and muscle damage biomarkers after running a marathon. J Strength Cond Res. April 29, 2019 [Epub ahead of print]. 